\title{
International Human Rights Law (2019)
}

\author{
Marlies Hesselman*
}

This section discusses the practice of UN human rights monitoring bodies, such as treaty bodies, UN Special Procedures and the Human Rights Council. While, unlike last year, no major instruments were adopted throughout 2019, in the form of General Comments or Guiding Principles, especially UN Special Procedures were very active in addressing disasters and climate change. Small Island Developing States (sIDs) play a leading role within the UN human rights system on such issues, including especially climate-leader Fiji, a very vocal player in the UPR this year, ${ }^{1}$ which also hosted the UN Special Rapporteur on Human Rights and the Environment for a country visit.

Because 2019 saw many developments on petitions at treaty bodies and the work of UN Special Procedures, the more day-to-day monitoring practices of the UN treaty bodies through the adoption of Concluding Observations, or the Universal Periodic Review of the Human Rights Council, are not addressed this year. ${ }^{2}$

* Lecturer in International Law, University of Groningen.

1 The uhri.ohchr.org database shows recommendations of Fiji to 23 countries in 2019, out of 28 total recommendations so far by this country. These include for example: HRC, 'Report of the Working Group on the Universal Periodic Review - Albania' (3 July 2019) UN Doc A/HRC/42/4, para. 95.29; HRC, 'Report of the Working Group on the Universal Periodic Review - Costa Rica' (5 July 2019) UN Doc Doc A/HRC/42/12, para. 111.46; HRC, 'Report of the Working Group on the Universal Periodic Review - Egypt' (27 December 2019) UN Doc A/HRC/43/16, 31.67; HRC, 'Report of the Working Group on the Universal Periodic Review Italy' (27 December 2019) UN Doc A/HRC/43/4, para. 148.123; HRC, 'Report of the Working Group on the Universal Periodic Review - Angola' (11 December 2019) UN Doc A/HRC/43/11, para. 146.80; HRC, 'Report of the Working Group on the Universal Periodic Review Ethiopia' (5 July 2019) UN Doc A/HRC/42/14, paras. 163.39-4O: 'ensure that the disaster risk management policy addresses existing and new risks of gender-based violence within the context of disaster risk reduction'. In its 2019 UPR Report Fiji itself also received many comments, e.g. HRC, 'Report of the Working Group on the Universal Periodic Review - Fiji' (23 December 2019) UN Doc A/HRC/43/8, paras. 28, 34, 41, 54, 63, 100, 108, 118, 119, 111, 130, 139.55, 139.61, 139.63, 139.67-68 and 139.94-95. See on post-disaster recovery also Barbados to Vanuatu: HRC, 'Report of the Working Group on the Universal Periodic Review - Vanuatu' (17 April 2019) UN Doc A/HRC/41/10, para. 9o.69.

2 The work of UN bodies is accessible via <uhri.ohchr.org > last accessed (as any subsequent URL) on 8 August 2020. An overview of the work of the Human Rights Council specifically is available through: UNGA, 'Report of the Human Rights Council' (2019) UN Doc A/74/53. In 2019, disaster-related comments were included in the following HRC Resolutions:

(C) MARLIES HESSELMAN, 2021 | DOI:10.1163/26662531_00201_026

This is an open access chapter distributed under the terms of the GC BY BNC 4.Policense•r. com04/26/2023 08:06:05AM via free access 
A remarkable new development in 2019 is that UN treaty bodies have received several communications on climate change under their Optional Protocols on complaints procedures.

In May 2019, a group of indigenous persons from the Torres Straight Islands submitted a petition to the Human Rights Committee, launching the case of Torres Straight Islanders v. Australia. ${ }^{3}$ The text of the petition was not made public, but according to press releases petitioners complain that their right to culture (art. 27 ICCPR), freedom from arbitrary interference with privacy, family and home (art. 17 ICCPR) and their right to life (art. 6 ICCPR) are violated. They complain about Australia's inadequate targets and plans for GHG mitigation and its failure to fund adequate coastal defence and resilience measures on the islands. Although this case remains pending, under pressure of the petition, applicants managed to secure an ASD \$25 million fund for the construction and repair of critical infrastructure on the islands, including seawalls, to protect against pending catastrophic impacts, like severe flooding and storm surges. ${ }^{4}$ The case proceeds at the UN, including in relation to requests on stronger GHG reduction targets and the phasing out of coal specifically.

On 23 September 2019, a group of well-known youth climate activists from around the world, including Greta Thunberg, Ridhima Pandey and 14 others, submitted a petition at the Committee on the Rights of the Child against five countries: Argentina, Brazil, France, Germany and Turkey. ${ }^{5}$ This petition is public and complains, inter alia, about violations of the right to life, the right

Resolution 40/7 (right to food), Resolution 40/14 (the rights of the child: empowering children with disabilities), Resolution 41/3 (enhancement of international cooperation in the field of human rights), Resolution 41/8 (consequences of child, early and forced marriage), 41/15 (mandate of the Special Rapporteur on the human rights of internally displaced persons), Resolution 41/16 (the right to education), and Resolution 41/21 (human rights and climate change).

3 Torres Straight Islanders $v$ Australia, Communication to the Human Rights Committee (13 May 2019) <http://climatecasechart.com/non-us-case/petition-of-torres-strait-islanders -to-the-united-nations-human-rights-committee-alleging-violations-stemming-from -australias-inaction-on-climate-change/>.

4 ClientEarth, 'Torres Strait Islanders win key ask after climate complaint' (ClientEarth, 14 February 2020) <https://www.clientearth.org/torres-strait-islanders-win-key-ask-after -climate-complaint $/>$.

5 Chiara Sacchi and 15 others $v$ Argentina, Brazil, France, Germany and Turkey, Communication to the Committee on the Rights of the Child, submitted under Article 5 of the Third Optional Protocol to the United Nations Convention on the Rights of the Child (23 September 2019) $<$ http://climatecasechart.com/non-us-case/sacchi-et-al-v-argentina-et-al/>. 
to health, the right to culture and the best interests of the child, due to States' failure to mitigate dangerous climate change and related climate disasterrisks - experienced both now and in the future - like extreme heat, wild fires, storms, floods, droughts, and sea-level rise. It relies on UNICEF reports on the extent of climate displacement already occurring as a result of increased big storms, intense rainfall, drought, and other climatic disasters, and stresses not only the physical impacts of climate-disasters on children, but also the mental health impacts.

The cases rely on important precedents of climate litigation, including the Dutch Urgenda case, which received a final judgement by the Dutch Supreme Court in October 2019. ${ }^{6}$ This court agreed with previous lower-level judgments that the Kingdom of the Netherlands is legally obliged to minimally reduce its GHG emissions by $25 \%$ by 2020 , compared to its GHG emissions levels of 1990 . A safe minimum reduction effort does not follow only or per se from international climate law, but also from other legal regimes, such as States' obligations under human rights law. ${ }^{7}$ The Supreme Court held that a 'minimal fair share' of positive obligations under the right to life and right to private life in arts. 2 and 8 of the European Convention on Human Rights (ECHR) could be 'concretized' with reference to the wide-spread international scientific, political and legal consensus on the urgency and requirements for climate mitigation in the short and longer term, as developed through the UN Framework Convention on Climate Change (UNFCCC), the Paris Agreement, its related Conferences of Parties (COPs), and the work of the Inter-governmental Panel on Climate Change - also supported by the Netherlands. ${ }^{8}$ This interpretation method aligns with a practice of 'common (European) consensus/ground' interpretation under the ECHR, inspired by Article 31(3)(c) of the Vienna Convention on the Law of Treaties and doctrines of systemic interpretation, whereby the wider 'international law background' to the question before it is taken into account. The UN Human Rights Committee recently observed a similar 'mutually reinforcing' relationship between international environmental law and the meaning of the right to life in its General Comment No. $36 .^{9}$

This section will certainly comment further on these cases next year.

6 Supreme Court of the Netherlands, State of the Netherlands $v$ Urgenda (Judgment of 2o December 2019) ECLI:NL:HR:2019:2007.

7 Ibid., paras. 6.3-6.6 and 7.3.1-7.3.6.

8 Ibid., paras. 5.1.-5.4.3, 6.1-6.6. and 7.2.11.

9 See for a summary, the contribution by Marlies Hesselman, 'Human Rights Law (2018), (2019) 1 Yearbook of International Disaster Law, 398-408. 
Finally, it is of interest to remark that on 24 October 2019, the UN Human Rights Committee adopted its views in the well-known climate refugee case of Teitiota $v$. New Zealand.$^{10}$ Teitiota, a Kiribati national, claimed protection under the right to life against expulsion to this sids due to his possible exposure to the dangerous effects of climate change, including sea level rise and other natural disasters. Scott discusses this case in his YIDL Section on 'Migration/ Refugee Law'"l

2

\section{Annual Report of UN Special Rapporteur on Extreme Poverty, Mr. Philip Alston, on Climate Change}

In his report of 17 July 2019, the UN Special Rapporteur on Human Rights and Extreme Poverty, Mr. Philip Alston, this year drew attention to the risks posed by climate change and climate-related disasters for those living in (extreme) poverty. According to the report, in 2017 disasters displaced twice the number of people than conflict, while people in poor countries died from disasters at rates seven times higher than in wealthy countries since 2000. Moreover, public authorities 'have a history of prioritizing wealthier areas for protection', which further endangers people in poverty. ${ }^{12}$

The report sets out the type of human rights obligations identified so far by UN human rights bodies in the area of climate change, both related to mitigation and adaptation. The conclusion is that treaty bodies so far felt more comfortable to address adaptation, procedural rights and impacts on specific groups, rather than offer detailed legal guidance on how to address the root cause of climate change, i.e. obligations to mitigate GHG emissions. ${ }^{13}$

The report is also exceptionally critical of the role of the private sector, and dominant neoliberal economy-orthodoxy, in both causing the problem of climate change, and in sleep-walking governments and others into market-based or market-friendly solutions to climate change, or accepting the privatization of disaster response activities (e.g. disaster preparedness services like laying sandbags, private white-glove firefighters, or private power

10 CCPR, 'Views adopted by the Committee under article 5 (4) of the Optional Protocol, concerning communication No. 2728/2016' (7 January 2020) UN Doc CCPR/C/127/D/2728/2016.

11 Matthew Scott, 'Migration/Refugee Law (2019)', in this volume.

12 HRC, 'Report of the Special Rapporteur on extreme poverty and human rights' (17 July 2019) UN Doc A/HRC/41/39, paras. 8-13.

13 Ibid., para. 24. 
generators).${ }^{14}$ Such practices engrain and worsen deep inequality gaps in disaster affected populations, especially amongst poorer and wealthier segments of society, which he dubs 'climate apartheid'. ${ }^{15}$

All in all, Alston blames 'all actors' in the human rights sphere, including UN human rights monitoring bodies, of complacency in devising suitable responses to the impending disaster(s) caused by climate change. In particular, human rights advocates and human rights bodies are called upon to rethink and articulate in a transformational manner, and with much greater clarity, precision and force what a rights-perspective requires from governments in practice. Aside from more forward legal reasoning, community activism, building coalitions, and bringing the UN human rights mechanisms to life are also mentioned. On the latter, he states that

Human rights treaty bodies and others should weigh in on questions that are already hotly contested in courthouses and parliaments, including how human rights obligations can be used to define the legal duties of States to reduce greenhouse gas emissions individually and at a global level, what the minimum actions are that States must take in line with the latest scientific guidance and whether human rights law gives rise to a certain threshold of action below which a State is in violation of its obligations. ${ }^{16}$

Regrettably, aside from identifying 'a range of steps that should be taken to begin to rectify the failure' of human rights monitoring bodies lack of more prescriptive guidance to States - e.g. in Concluding Observations - Alston also sees no space to 'provide detailed recommendations' in this regard in this particular report either. ${ }^{17}$

On the overall role of UN Special Procedures, he further argues that in the near future, the Coordination Committee of Special Procedures must take action to 'ensure a systemic response to climate change that considers the full range of options for coming up with a more creative, urgent and system-wide approach, led by the Special Rapporteur on the environment'. ${ }^{\prime}$

\footnotetext{
$14 \quad$ Ibid., para. $5^{1 .}$

15 Ibid., paras. $33-38$ and $47-51$.

16 Ibid., para. 81.

17 Ibid., paras. 81-87.

18 Ibid., para. 25 .
} 


\section{Annual Report and Country Visit to Fiji of UN Special Rapporteur Environment, Mr. David Boyd, on Climate Change}

The UN Special Rapporteur on the Environment published his second report exclusively devoted to climate change in the same month as the aforementioned report. ${ }^{19}$ So far, the broad category of "disasters" has not received ample attention as a specific concern by this special procedure: reports so far focused on the right to a healthy environment, the right to clean air, and human rights and climate change. ${ }^{20} \mathrm{Mr}$. Boyd recognized in recent years that the 'right to healthy environment' specifically includes the component of a 'stable climate' as a 'vital element and absolutely essential to human life and well-being', and disasters are typically discussed in this context.

The prevention of, preparedness for and response to climate-related disasters is addressed in the 2019 report, including with attention to those countries and persons more vulnerable to impacts (e.g. low-come countries, sIDs, (rural) women, children, indigenous people). ${ }^{21}$ At the same time, the report focuses on mitigation mostly: the section discussing 'human rights obligations related to climate change' does not include a single reference to disasters. The recommendation section however provides, somewhat vaguely, that adaptation measures need to be dramatically accelerated, as well as integrate disaster risk measures. As a novel point not often sufficiently stressed, States are also recommended to provide adequate social protection mechanisms to reduce vulnerability to climate-related disasters and stresses, thereby enhancing people's resilience, as well as to prioritize nature-based and ecosystem-services based adaptation as a way of buffering impacts of extreme weather and slowonset events. ${ }^{22}$ National adaptation plans or programmes must 'address both extreme weather disasters and slow-onset events' and build or upgrade infrastructure to be climate resilient (e.g. water, sanitation, health and education facilities).

19 HRC, 'Report of the Special Rapporteur on the issue of human rights obligations relating to the enjoyment of a safe, clean, healthy and sustainable environment' (15 July 2019) UN Doc A/74/161.

20 See, for an overview of this special procedure's work: <https://www.ohchr.org/EN/Issues/ Environment/SREnvironment/Pages/AnnualReports.aspx $>$.

21 HRC Report (n 19) paras. 45-51.

22 Ibid., para. 86(d). See on this point in relation to developments in international environmental law also last year's YIDL section on international environmental law: Marlies Hesselman, 'International Environmental Law (2018)', (2019) 1 Yearbook of International Disaster Law, 436-444. 
Finally, consistent with the Sendai Framework on Disaster Risk Reduction (DRR), States must develop DRR and management strategies, early warning systems, emergency response plans, and provide disaster relief and humanitarian assistance in emergencies. ${ }^{23}$ In particular, 'a rights-based approach should be applied in order to tackle the root causes of vulnerability, such as poverty, inequality, discrimination and marginalization, and not merely the symptoms of climate change impacts. ${ }^{24}$

Similar observations, and some more specific ones, are visible in this Special Rapporteur's report on a country visit report to Fiji in December 2018, when Fiji was still recovering from the impact of Tropical Cyclone Winston, a category 5 storm of February 2016. ${ }^{25}$ Cyclone Winston killed 44 people on Fiji and caused massive destruction. The Rapporteur lauded the general disaster response of Fiji, noting that early warning and disaster preparedness reduced human losses and allowed for quick repair of essential infrastructure. Recovery was also aided by quickly scaling up social protection programmes, such as the Poverty Benefit Scheme, the Care and Protection Allowance and the Social Pension Scheme. ${ }^{26}$ The visit also highlighted some remaining structural drivers of vulnerability to climate-related natural disasters in Fiji, such as the poor housing quality of those living in informal settlements on the outskirts of cities and towns, e.g. in relation to repeated flooding, and poor access to services. ${ }^{27}$

An important question is whether the reports live up to the call for action by the UN Special Rapporteur on Extreme Poverty to provide (more) detailed guidance to States (see previous section). In fact, this Special Rapporteur's engagement with disaster issues so far, generally, has been fairly minimal, and the comments on adaptation are still somewhat vague. It seems that especially his general climate change report has been used to provide many more detailed comments on mitigation specifically. These include calls for much more ambitious action on climate mitigation, 'at a rate consistent with their international commitments', and on track towards 'reducing greenhouse gas emissions by at least 45 per cent by 2030 (as calculated by the Intergovernmental Panel on

\footnotetext{
23 Ibid., para. 86(c).

24 Ibid., para. 85.

25 HRC, 'Report of the Special Rapporteur on the issue of human rights obligations relating to the enjoyment of a safe, clean, healthy and sustainable environment: Visit to Fiji' (27 December 2019) UN Doc A/HRC/43/53/Add.1.

26 Ibid., para. 43-44 and 51. Fiji currently devotes approximately 10 percent of its total budget to reducing climate risks and preparing for natural disasters.

27 Ibid., para 3 .
} 
Climate Change). ${ }^{28}$ The report also cites the Urgenda case precedent. ${ }^{29}$ More specifically, all States should 'prepare rights-based deep decarbonization plans intended to achieve net zero carbon emissions by 2050, in accordance with article 4(19) of the Paris Agreement'. ${ }^{30}$ They are also asked, inter alia, to 'immediately terminate all fossil fuel subsidies, except for clean cookstove programmes', to 'stop building new coal-fired power plants unless equipped with carbon capture and storage technology' or to retrofit existing coal-fired power plants in this manner, to keep fossil fuels in the ground as much as possible, to curb negative influences by industries, or to secure zero-carbon transportation.' ${ }^{31}$

\section{Annual Report and Country Visit of UN Independent Expert on Older Persons, Ms. Rosa Kornfeld-Matte, on Older Persons in Emergency Settings}

The UN Independent Expert on Older Persons published her first report specifically dedicated to the rights of older persons in emergency situations, on 4 July 2019, offering very detailed guidance on the rights of older refugees and climate-displaced persons, or older persons facing conflict, emergency or disaster situations. The report benefitted from inputs by a broad range of UN and non-UN events. ${ }^{32}$

This report is a very welcome addition to the clarification of the rights of older persons in times of disaster. It meticulously raises awareness about a broad range of vulnerabilities faced by older persons in several stages of disasters, including during situations of displacement. It highlights how 'age often compounds other forms of vulnerability or inequality - such as gender, race, education level, income, health status, or access to justice - that accumulate during a lifetime'. Older persons' vulnerability to emergency situations is exacerbated by a lack of rights enjoyment in pre-disaster settings. ${ }^{33} \mathrm{In}$ particular, this Expert draws attention to the fact that the category of "older persons" is extremely heterogenous, and that vulnerabilities faced by older persons in emergency contexts may be both intrinsic (e.g. result from poor

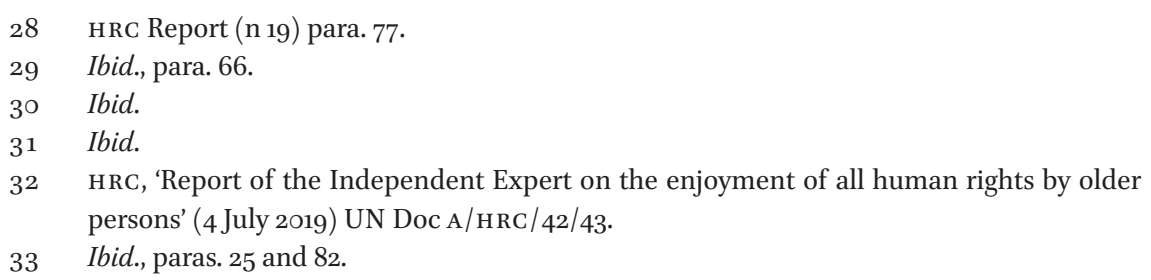


health, disability or frailty), extrinsic (e.g. result from low income, low degree of literacy or remote place of residence) or systemic (e.g. a lack of disaggregated data, failure to assess needs correctly, or to monitor the effectiveness of assistance) ${ }^{34}$ Of specific interest is that the Expert specifically highlights the impact of 'digitalization' of emergency management and humanitarian response on the elderly, especially in terms of the possible challenges with low digital literacy rates. ${ }^{35}$ Similarly, "with the increasing use of technology in humanitarian action, including during the assessment phase, there is a risk of overlooking the digitally invisible older persons.' ${ }^{36}$

In the 'absence of a dedicated instrument on older persons' the Independent Expert sets out in detail how the existing international and regional legal frameworks apply, and identifies specific 'human rights impact and challenges' in relation to the right to housing, right to social security, right to work, right to food, right to health and not to be subjected to violence, maltreatment and abuse. She draws attention to several human rights provisions specifically providing protection to older persons in times of emergency, like art. 11 of the Convention on the Rights of Persons with Disabilities, art. 14 of the African Charter's Protocol on the Rights of Older Persons, or art. 29 of the Inter-American Convention on Protecting the Human Rights of Older Persons. She equally affirms key interpretative guidance available through instruments like CEDAW General Comment No. 27 (2010) on older women's rights, the Global Pact on Refugees, the UN Guiding Principles on Internal Displacement, or the African Union's Kampala Convention on protection and assistance for internally displaced persons.

Also in 2019, her country report about a visit to Mozambique, struck by both cyclones Idai and Kenneth, equally begins with a specific section dedicated to the situation of older persons in post-disaster settings, and formulates several recommendations, especially relating to exclusion, poverty, resettlement and all forms of violence, abuse, neglect and maltreatment. ${ }^{37}$

\footnotetext{
34 Ibid., paras. 24-25.

35 Ibid., paras. 71-78.

$36 \quad$ Ibid., para. 87 .

37 HRC, 'Report of the Independent Expert on the enjoyment of all human rights by older persons: Visit to Mozambique' (17 July 2019) UN Doc A/HRC/42/43/Add.2.
} 


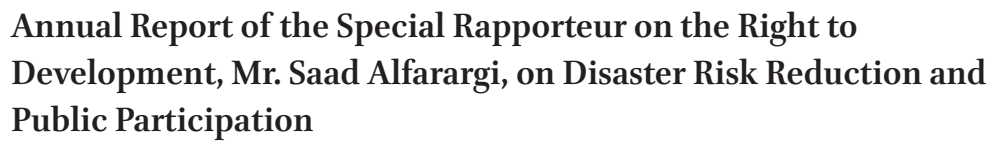

On 15 July 2019, the UN Special Rapporteur on the Right to Development published his first report explicitly devoted to disaster related issues. The report deals with the intersections of the right to development, sustainable development and disaster risk reduction, and focuses on 'participatory processes related to the planning, monitoring and implementation of disaster risk reduction measures and policies'. ${ }^{38}$ It notes on the latter point that

The right to development entitles every human being and all peoples to participate in, contribute to and enjoy economic, social, cultural and political development. In the spirit of the Declaration on the Right to Development, the entitlement to participate should be extended to an entitlement for all to participate in planning and decision-making related to disaster preparedness and disaster risk reduction.

This report primarily records best practices in Montenegro, Ecuador, Mexico, Ukraine, Tanzania, Switzerland, Portugal, Lebanon and Pakistan, submitted by States and other stakeholders. Instead of offering guidance on the content of the right to development as such, the report chiefly emphasizes the content of the UN Sendai Framework for Disaster Risk Reduction as the leading framework on this point. It for example cites the reference to the right to development in that framework, along with other recommendations relevant to the theme of this report, e.g. the need to engage in 'all-of-society engagement and partnership and empowerment' or ensuring 'inclusive, accessible and non-discriminatory participation, paying special attention to people disproportionately affected by disasters, in particular the poorest'.

Based on the works of 'scholars and practitioners' mostly, the report then draws attention to the plight of persons with disabilities specifically, including specifically poor disabled women. Why this group is singled out amongst all groups affected by disasters, is not abundantly clear. Supposedly this group is perceived as facing the greatest obstacles for participation in DRR. Overall, the report could have benefitted from reiterating any guidance so far available on this topic in general, and from the Committee on the Rights of

38 HRC, 'Report of the Special Rapporteur on the right to development' (15 July 2019) UN Doc A/74/163. 
Persons with Disabilities specifically. The latter has a rich practice of discussing access to disaster information specifically. ${ }^{39}$ Similarly, CEDAW General Recommendation No. 37 (2018) includes a range of comments on participation of women in disaster risk reduction, and the extremely interesting work on the 'right to participation' by the UN Special Rapporteur on Extreme Poverty and Human Rights could have been of interest. ${ }^{40}$

All in all, this report, while certainly welcome attention to the topic of human rights and disaster risk reduction by yet another Special Rapporteur in the UN human rights system, is weak on providing practical legal guidance to States. This may be due to the nature of the right to development, but it may also result from the fragmented development of disaster law generally, especially the absence of a single treaty or other type referencing point. It could be argued that the broader topic of 'climate change' has such a clear anchor point in the form of the UNFCCC, and is therefore more consistently addressed by UN human rights bodies - even if obstacles also still exist. While the reference to the Sendai Framework is applauded and could be seen an anchor point for DRR and human rights, it is unclear from this report how human rights law provides concrete legal 'back-up' or 'teeth' to this framework.

In terms of the (weak) recommendations, this Rapporteur attaches great importance to the establishment of national platforms for disaster risk reduction, as such are perceived to be multi-stakeholder oriented and nationally owned, while also mapping of affected persons is recommended as a stepping stone for participation. Of specific (novel) interest, is the Rapporteur's call to enhance civil society's own capacity for disaggregated data gathering on DRR, which may stimulate innovative 'citizen science' approaches to bridge data collection gaps.

39 See e.g. Marlies Hesselman, 'Access to Disaster Risk Information, Early Warning and Education and Awareness: Implementing the Sendai Framework through International Human Rights Law' in Katja Samuel and Marie Aronsson-Storrier (eds), International Law and Disaster Risk Reduction (CUP 2019) 188-215.

40 See e.g. HRC, 'Report of the Special Rapporteur on extreme poverty and human rights, Ms. Maria Magdalena Sepúlveda Carmona on the right to participation of people living in poverty' (11 March 2013) UN Doc A/HRC/23/36. 